\title{
Bowen's Disease on Both Hands Caused by Constant Exposure to Chemical Agents
}

\author{
Je Yeon Byeon, Hwan Jun Choi, Jun Hyuk Kim, Young Man Lee \\ Department of Plastic and Reconstructive Surgery, College of Medicine, Soonchunhyang University, Cheonan, Korea
}

\begin{abstract}
Bowen's disease (BD) is a neoplastic skin disease and is also known as squamous cell carcinoma in situ of the skin. Etiological factors include irradiation, carcinogens, immunosuppression, and viruses. A 50-year-old man presented with persistent, progressive, slightly raised, red, and crusted plaque-like masses that occurred suddenly on both hands. A wide excision and local advancement flap were used for the masses. Atypical squamous cells proliferated through the entire thickness of the epidermis that was diagnosed as BD. This patient had been working with construction materials and was in the printing business. He also had a history of constant hand exposure to substances such as arsenic and tar; thus, it was possible that they contributed to this occurrence of BD. No sign of recurrence was detected at the 6 months follow-up. Therefore, early diagnosis and management are particularly important.
\end{abstract}

Keywords: Bowen's disease, Squamous cell carcinoma in situ, Hand, Arsenic, Carcinogen

\section{Introduction}

Bowen's disease (BD) is a neoplastic skin disease also known as squamous cell carcinoma (SCC) in situ of the skin. John Templeton Bowen first described Bowen's disease as precancerous dermatosis in 1912., ${ }^{1,2}$ BD is an early stage intraepidermal form of SCC. BD progresses to invasive carcinoma in 3-5\% of cases, with the capability to develop metastases. ${ }^{3}$ It occurs with a slight female preponderant incidence and most commonly in elderly people. Peak incidence of the disease occurs in the seventh decade of life. BD usually presents as an asymptomatic, slow-growing scaly or crusted erythematous plaque, which is sharply demarcated and superficial on palpation. ${ }^{4}$ Etiological factors include irradiation, carcinogens (arsenic), immunosuppression, and viruses (human papillomavirus 16 [HPV 16]). The accurate percentage of causes of BD is not present. The majority of studies report that SCC in situ occurs mainly on sun-exposed sites, with more recent studies suggesting the most common site being the head and neck (29-54\%) however, the lower limbs seem to be affected more in women than in men. ${ }^{5}$ Older, U.K.-based studies have reported that the majority of patients (60-85\%) have SCC in situ on the lower legs, which may indicate that the sun exposure pattern is different in countries with lower rates of sunshine. ${ }^{5}$ Less common variants include pigmented, subungual, periungual, palmar, genital, perianal and verrucous SCC in situ..$^{5}$ So, This is the rare case that we diagnosed and treated a patient with BD occurring on both hands caused by unexpected harmful chemical agents.

\begin{tabular}{l} 
Case Report \\
updates \\
Received: May 9, 2017 \\
Accepted: May 12, 2017 \\
Corresponding author: \\
Hwan Jun Choi, M.D., Ph.D. \\
Department of Plastic \& Reconstructive \\
Surgery, Soonchunhyang University \\
Cheonan Hospital, Soonchunhyang \\
University College of Medicine, 31 \\
Suncheonhyang 6-gil, Dongnam-gu, \\
Cheonan 31151, Korea \\
Tel: +82-41-570-2195 \\
Fax: +82-41-574-6133 \\
E-mail: medi619@ @hanmail.net \\
No potential conflict of interest relevant to this \\
article was reported. \\
\hline This is an Open Access article distributed under the \\
terms of the Creative Commons Attribution Non- \\
Commercial License (http://creativecommons.org/ \\
licenses/by-nc/4.0/ which permits unrestricted non- \\
commercial use, distribution, and reproduction in any \\
medium, provided the original work is properly cited. \\
@ 2017 The Korean Wound Management Society
\end{tabular}




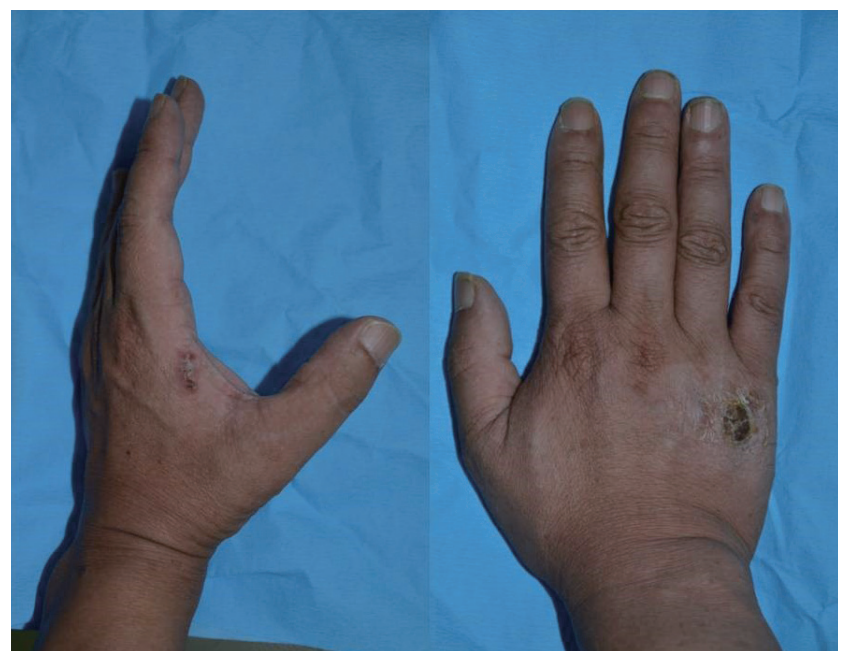

Figure 1. Preoperative photograph. Slightly raised, red, and crusted plaque-form masses which diagnosed to Bowen's disease on both hands.

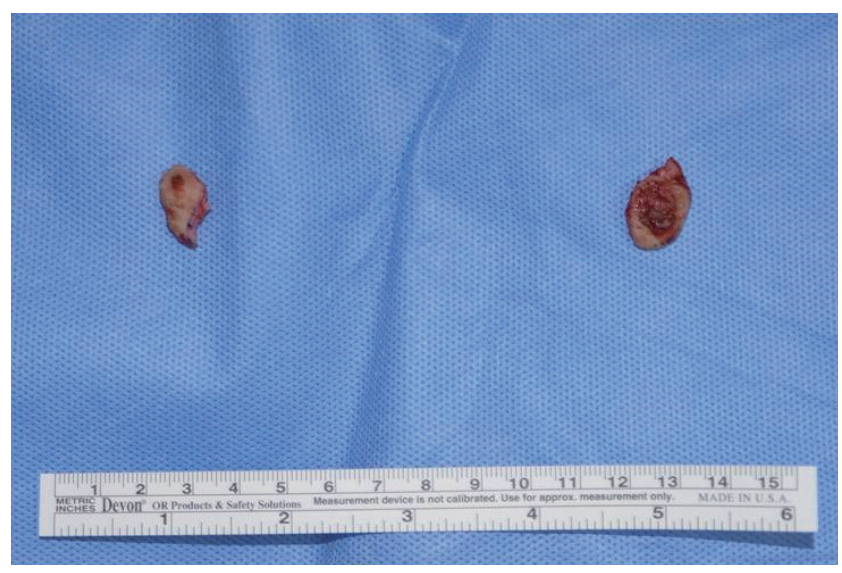

Figure 2. Postoperative photograph. A $1.2 \times 1.1 \mathrm{~cm}^{2}$ mass on the right hand and a $1.2 \times 0.5 \mathrm{~cm}^{2}$ mass on the left hand.

\section{Case report}

The patient was a 50-year-old man with persistent, progressive, slightly raised, red, and crusted plaque-form masses that occurred suddenly on both hands 2 years ago (Figure 1 ). No induration was detected in the lesion or in the surrounding skin. No specific findings were observed on a radiograph or after taking a family history. The patient had been working continuously with construction materials and paints for 3 years and was exposed to various chemical substances such as arsenic and tar.

The masses $\left(1.2 \times 1.1 \mathrm{~cm}^{2}\right.$ on the right hand and $1.2 \times 0.5$ $\mathrm{cm}^{2}$ on the left hand) were excised widely with $3 \mathrm{~mm}$ free margin in August 2013, and a local advanced flap was used

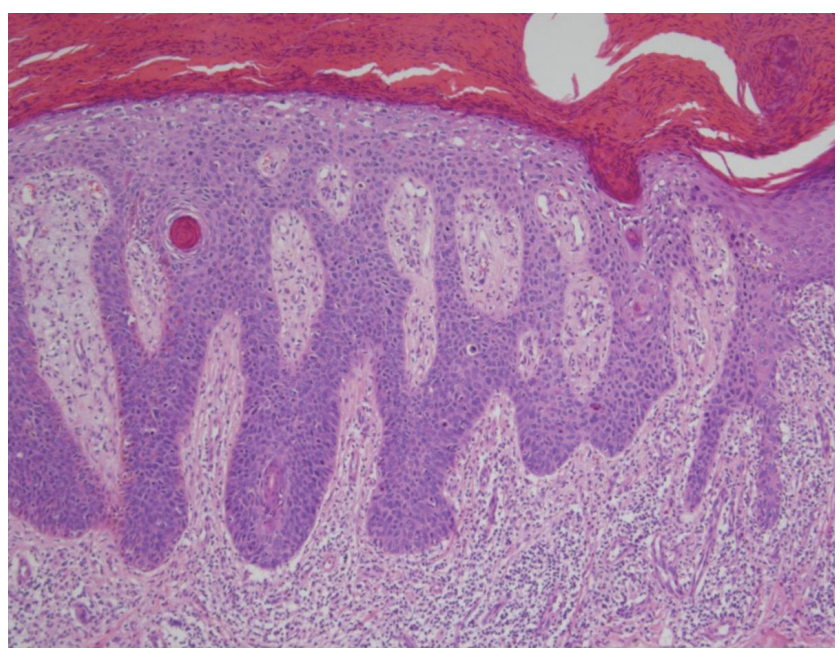

Figure 3. Histopathology of the mass. Highly atypical squamous cells proliferating throughout the entire thickness of the epidermis with dermal inflammation. The entire tumor was confined to the epidermis and did not invade the dermis.

(Figure 2). The gross specimen was shaped irregularly, and the resection margin was negative. Atypical squamous cells proliferated through the entire thickness of the epidermis on a histopathological examination of the surgical specimen. The masses on both hands were diagnosed as BD. The highly atypical cells including keratinocytes, causing epidermal disorganizing, were confined to the epidermis and did not invade the dermis (Figure 3). No signs of recurrence were observed at the 6 months follow-up.

\section{Discussion}

$\mathrm{BD}$ is intraepidermal epidermoid carcinoma that invades the skin or mucous membranes. The exact cause of the disease is unknown but known etiological factors include: 1) irradiation, such as sun exposure, photochemotherapy, and radiotherapy; 2) carcinogens, such as arsenic; 3) immunosuppression, such as therapeutic immunosuppression or acquired immune deficiency syndrome; and 4) oncogenic HPV types, such as HPV 16 which is associated with the development of cervical canceer. ${ }^{4}$ BD lesions occur most frequently on parts of the body chronically exposed to sunlight. The lesions are typically scaly, well-defined plaques, with a flat, velvety, or verrucous surface that is often pigmented and may resemble melanoma. Therefore, early diagnosis and management of $\mathrm{BD}$ are important. The occurrence of $\mathrm{BD}$ on the hand dorsum is extremely rare, except in cases of multiple $\mathrm{BD}$ associated with chronic arsenic exposure. Cases of $\mathrm{BD}$ 
that include several masses are known to be related to arsenic exposure. Chronic arsenic exposure leads to the development of hyperpigmented patches and small hypopigmented patches on the skin of the trunk. Eventually It cause cancer of outermost layer of skin and also activate HPV. ${ }^{1}$ Our patient was working with construction and printing materials 3 years ago, and his hands were constantly exposed to substances such as arsenic; thus, this may have contributed to this occurrence of $\mathrm{BD}$.

The treatment of $\mathrm{BD}$ varies with body site, lesion size, equipment available and the perceived potential for poor wound healing such as lower legs. ${ }^{5}$ Treatments for BD include topical 5-fluorouracil or imiquimod cream application, surgery, cryotherapy, and photodynamic therapy (PDT). ${ }^{6}$ Nowdays, surgery including wide excision with 3-5 mm free margin is preferred because of the low recurrence rate, but it can result in hypertrophic scarring or contracture, particularly in hand and lower leg lesions.

In conclusion, the scale or hyperkeratotic skin lesion in the patients with chronic exposure of arsenic is carefully evaluated and confirmed to diagnosis malignancy through histological examination. It is important to early detection and treatment of these patients. Furthermore, in the future, the combination therapy such as PDT with simple excision and some new method will be taken center stage.

\section{Acknowledgments}

This work was supported by Soonchunhyang University Research Fund.

\section{References}

1. Yamaoka H, Ikoma N, Kato M, et al. Multiple Bowen's disease in a patient with a history of possible arsenic exposure: a case report. Tokai J Exp Clin Med 2011;36:53-7.

2. Bath-Hextall FJ, Matin RN, Wilkinson D, et al. Interventions for cutaneous Bowen's disease. Cochrane Database Syst Rev 2013;24:CD007281.

3. Grundmeier N, Hamm H, Weissbrich B, et al. High-risk human papillomavirus infection in Bowen's disease of the nail unit: report of three cases and review of the literature. Dermatology 2011;223:293-300.

4. Firooz A, Farsi N, Rashighi-Firoozabadi M, et al. Pigmented Bowen's disease of the finger mimicking malignant melanoma. Arch Iran Med 2007;10:255-7.

5. Morton CA, Birnie AJ, Eedy DJ. British Association of Dermatologists' guidelines for the management of squamous cell carcinoma in situ (Bowen's disease) 2014. Br J Dermatol 2014;170:245-60.

6. Sooeun J, Suekyung K, Youchan K, Photodynamic therapy in bowen disease of the first web space of the hand, Ann Dermatol Vol. 2015;27:76-8. 